\title{
The Constitutive Expression of the V Gene of Parainfluenza virus 5 Affects the Growth Properties of Bovine Herpesvirus 5
}

Francisco Esmaile de Sales Lima ${ }^{1 *}$, Helena Beatriz Ruthner Batista ${ }^{1}$, Fabrício Souza Campos $^{1}$, Hiran Castagnino Kunert Filho ${ }^{1}$, Samuel Cibulski ${ }^{2}$, Fernando Finoketti ${ }^{1}$, Thalita Arantes $^{1}$, Fernando Spilki ${ }^{3}$, Paulo Michel Roehe ${ }^{2}$, Franciscus Antonius Maria Rijsewijk ${ }^{1}$ and Ana Cláudia Franco ${ }^{1}$

${ }^{1}$ Laboratório de Virologia; Departamento de Microbiologia; Imunologia e Parasitologia; Instituto de Ciências Básicas da Saúde;Universidade Federal do Rio Grande do Sul; Porto Alegre - RS - Brasil. ${ }^{2}$ Instituto de Pesquisas Veterinárias Desidério Finamor; Eldorado do Sul - RS - Brasil. ${ }^{3}$ Laboratório de Microbiologia Molecular; Universidade Feevale; Novo Hamburgo - RS - Brasil

\begin{abstract}
This study aimed to analyze the effect of the expression of Parainfluenza virus 5 (PIV5) V protein in bovine cells on the replication of Bovine herpesvirus 5 (BoHV-5). Growth properties of BoHV-5 were evaluated in parental and PIV5 transfected cells. In one-step growth experiments, the BoHV-5 reached higher titers at earlier time points in the transfected cells when compared to the parental cells. The mean plaque size produced by the BoHV-5 in transfected cells was larger than the parental cells. This indicated that the expression of the PIV5 V gene facilitated the release and cell-to-cell spread of BoHV-5 in bovine cells.
\end{abstract}

Key words: BoHV-5, V mRNA, transfection

\section{INTRODUCTION}

Bovine herpesvirus 5 (BoHV-5), the etiological agent of neurological infections of cattle (Delhon et al. 2003), is able to induce different mechanisms of innate and acquired immunity. An important outcome of innate antiviral responses is the production and secretion of type I interferons (IFN-I, e.g. IFN $\alpha$ and IFN $\beta$ ) and subsequent auto and paracrine activation of signaling pathways via IFN-I receptors, which ultimately limit virus replication and spread. Following virus infection, the induction of IFN-I occurs in three phases and requires activation of different signaling pathways.
In the first phase, pattern recognition receptors (PRRs, e.g Toll-like receptors) interact with the conserved viral motifs, resulting in the production of IFN $\beta$. In the second phase, the binding of IFN $\beta$ to its IFN-I receptor and signaling via the Signal Transducer and Activator of Transcription molecules STAT1 and STAT2 activates the transcription of IFN-stimulated genes (Platanias 2005).

A closely related virus, bovine herpesvirus 1 (BoHV-1), expresses a protein, named bovine infected cell protein 0 (bICP0), which blocks the IFN-I signaling (Everett 2000; Saira et al. 2007). BoHV-5 expresses a bICP0 homolog, and it has

*Author for correspondence: esmaile.sales@gmail.com 
been recently demonstrated that bICP0 of BoHV -5 can complement its BoHV-1 homolog (Steiner et al. 2010). It is, therefore, likely that the BoHV-5 bICP0 protein is able to block the host IFN-I production in the same way as its BoHV-1 counterpart. The present study analyzed the interactions between the IFN-I receptor signaling and the replication of BoHV-5.

\section{MATERIALS AND METHODS}

Cells resistant to bovine viral diarrhea virus (CRIB) were transfected with the Parainfluenza virus 5 (PIV5) V gene, previously used to block the IFN-I receptor signaling in the bovine cells and subsequently infected with BoHV-5 strain ISO 45/97. The plasmid used for the transfection was pEF.IRES.neo.SV5 V/P, a construct that contained the PIV5 V/P gene as well as the gene for G418 resistance. CRIB cells were transfected with Lipofectamine2000 ${ }^{\mathrm{TM}}$ (Invitrogen) according to the manufacturer's instructions. To isolate the cells containing the plasmid, transfected cells were grown in the presence of Geneticin ${ }^{\mathrm{TM}}$ (Invitrogen), and resistant colonies were isolated. The Geneticin resistant colonies obtained were submitted to DNA extraction and conventional PCR to detect the V gene. A q RT-PCR using SYBR Green fluorescence was developed in order to detect the presence of the V mRNA. Briefly, total RNA was extracted from the confluent cell monolayers as well as from the non-transfected CRIB cells using RNAqueous Kit (Ambion, Austin, TX) and treated with Ambion ${ }^{\circledR}$ TURBO ${ }^{\mathrm{TM}}$ DNase. The RNA was reverse transcribed using Oligo (dT) primers for the cDNAs synthesis. The primers used were based on the sequence of the Porcine parainfluenza virus $\mathrm{P}$ gene. The positive colonies were named CRIB/V and used for in vitro growth experiments. The plaque size assay and one-step growth curves were performed as described previously in triplicate (Franco et al. 2007). Statistical analysis was performed using the Student's $t$-test and the analysis of variance (ANOVA); the least significant difference at $p=$ 0.05 was determined. The term "significant" (statistically significant) in the text meant $p \leq 0.05$.

\section{RESULTS AND DISCUSSION}

It was estimated that about $10^{4}$ plasmid copies were present in $50 \mathrm{ng}$ of genomic DNA. This low copy number in the CRIB/V colonies could be the result of a natural selection for the cells with a low PIV5 V expression, because overexpression of the PIV5 V protein in the cells could slow down the cell cycle (Lin and Lamb 2000). The qRT PCR revealed the presence of $\mathrm{V}$ mRNA in all CRIB/V clones analyzed, indicating that the $\mathrm{V}$ protein expression occurred in these cells (data not shown).

The plaque sizes of BoHV-5 in CRIB/V were significantly larger $(3.0+/-0.4 \mathrm{~mm})$ than the ones in CRIB cells $(1.5+/-0.8 \mathrm{~mm}, \mathrm{p}=0.0001$, Fig. 1$)$. In agreement with other results, Barreca and O'Hare (2004), after the transfection with the same plasmid, showed that Human Herpesvirus 1 (HHV-1) progressed more rapidly and produced larger plaques in MDBK/V cells than in MDBK cells. These results showed that the blockage of the IFN-I receptor signaling had a positive effect on BoHV-5 replication and viral plaque production.

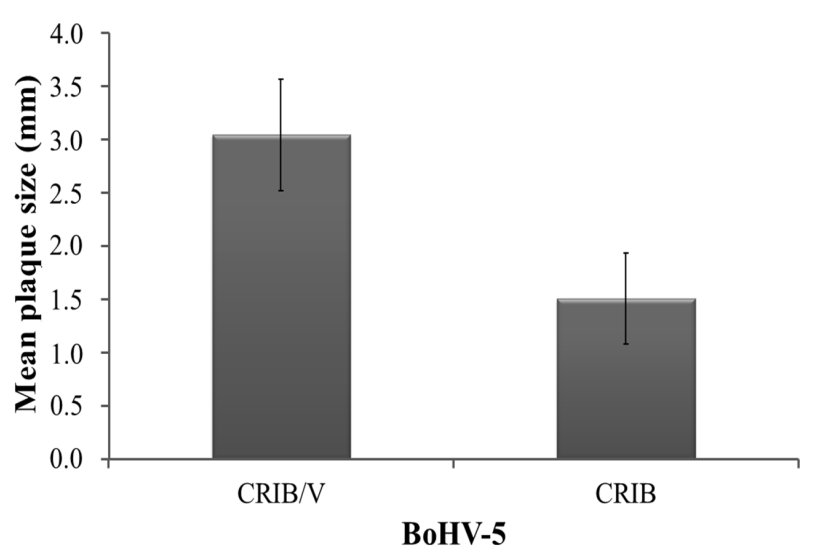

Figure 1 - Graphical presentation of the mean plaque sizes ( $\mathrm{mm}$ ) in CRIB and CRIB/V cells with their standard deviations. The values were estimated by measuring 50 viral plaques of each cell line infected with ISO $45 / 97$ of BoHV-5.

The one-step growth curves of BoHV-5 on CRIB and CRIB/V cells are shown in Figure 2. Infectious viruses were detected earlier in the CRIB/V cells (at $5 \mathrm{~h}$ post-infection - p.i) than in CRIB cells (at 9 h p.i.). From 5 h p.i. on until $13 \mathrm{~h}$ p.i. the ISO $45 / 97$ titers were significantly higher in the CRIB/V than in the CRIB cells. The maximum difference in virus titers calculated was $1 \log _{10}$ and occurred at $7 \mathrm{~h}$ p.i. From 15 h p.i. on the virus titers in both cells did not differ significantly and the virus reached similar amounts 
at $48 \mathrm{~h}$ p.i. In previous studies, Young et al. (2003) produced different human cell lines expressing the PIV5 V protein to block the IFN-I receptor signaling and observed that respiratory syncytial virus (RSV) and bunyamwera virus, an Orthobunyavirus, could grow to titers 10 to 4000 fold higher in the IFN-I non-responsive cells than in the parental cells. On the other hand, Sherwood et al. (2007) analyzed the replication of human enteric adenovirus type 40 (HAdV-40) in 293PIV5 V cells in comparison with the parental 293 cells and showed that the resulting virus yields in both cells was more, or less the same at $12 \mathrm{~h}$ p.i. It was recently demonstrated that a protein of BoHV1 (bICP0) blocked predominantly the first phase of the IFN-I induction (Saira et al. 2007 and 2009). Although BoHV-5 bICP0 could act in a similar way, present data indicated that the constitutive expression of the PIV5 $\mathrm{V}$ gene and consequent blocking of the IFN-I signaling in CRIB/V was responsible for the observed growth advantage of BoHV-5 in CRIB/V cells, especially when the growth curves (during the first hours post infection) and viral plaque sizes were analyzed.

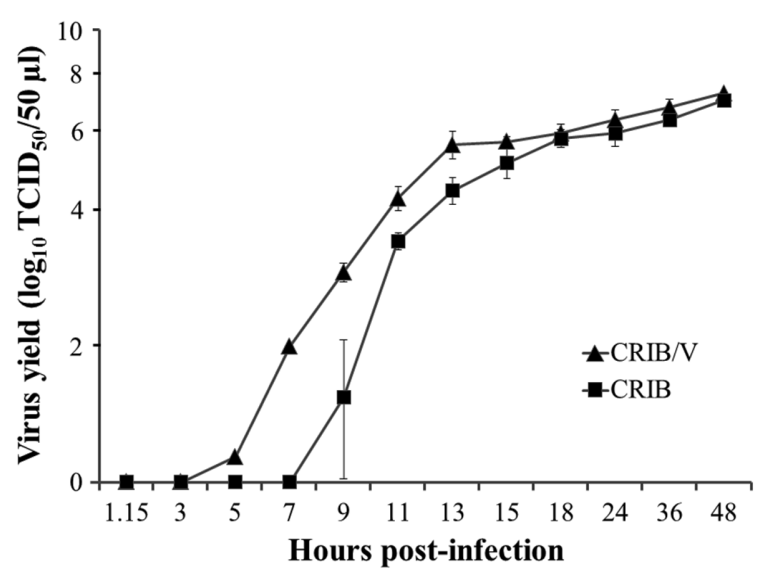

Figure 2 - Growth kinetics of BoHV-5 ISO 45/97 in CRIB and CRIB/V cells. Virus titers are expressed as $\mathrm{TCID}_{50} / 50 \mu \mathrm{L}$ and indicated on a $\log _{10}$ scale.

These results indicated that blocking the signaling via the IFN-I receptor by the PIV5 $\mathrm{V}$ protein facilitated the penetration, release and cell-to-cell spread of BoHV-5 in bovine cells. These data suggested that although BoHV-5 blocked (part of) the innate IFN-I responses, it was still sensitive to the antiviral effects of IFN-I during the early stages of infection.

\section{ACKNOWLEDGEMENTS}

The authors are thankful to R. Randall for kindly providing the plasmid. Financial support: National Council of Technological and Scientific Development (CNPq). We dedicate this article in memory of Fransciscus Antonius Maria Rijsewijk.

\section{REFERENCES}

Barreca C, O'Hare P. Suppression of herpes simplex virus 1 in MDBK cells via the interferon pathway. $J$ Virol. 2004; 78: 8641-8653.

Delhon G, Moraes MP, Lu Z, Afonso CL, Flores EF, Weiblen R, et al. Genome of bovine herpesvirus 5. $J$ Virol. 2003; 77: 10339-10347.

Everett RD. ICP0, a regulator of herpes simplex virus during lytic and latent infection. Bioessays.2000; 22: 761-770.

Franco AC, Hübner SO, Oliveira AP, Batista HBCR, Roehe PM, Rijsewijk F. Construction and characterization of a bovine herpesvirus 5 mutant with a deletion of the gI, gE and US9 genes. Braz $J$ Microbiol. 2007; 38: 667-673.

Lin GY, Lamb RA.The paramyxovirus simian virus $5 \mathrm{~V}$ protein slows progression of the cell cycle. $J$ Virol. 2000; 74: 9152-9166.

Platanias LC. Mechanisms of type-I and type-IIinterferon-mediated signaling. Nat Rev Immunol. 2005; 5: 375-386.

Saira K, Zhou Y, Jones C. The infected cell protein 0 encoded by bovine herpesvirus 1 (bICP0) induces degradation of interferon response factor 3 and, consequently, inhibits beta interferon promoter activity. J Virol. 2007; 81: 3077-3086.

Saira K, Zhou Y, Jones C. The infected cell protein 0 encoded by bovine herpesvirus 1 (bICP0) associates with interferon regulatory factor 7 and consequently inhibits beta interferon promoter activity. J Virol. 2009; 83: 3977-3981.

Sherwood V, Bugert HG, Chen YH, Sanghera S, Katafigiotis S, Randall RE, Connerton I, et al. Improved growth of enteric adenovirus type 40 in a modified cell line that can no longer respond to interferon stimulation. J Gen Virol. 2007; 88:71-76.

Steiner F, Zumsteg A, Vogt B, Ackermann M, Schwyzer, M. Bovine herpesvirus 5 BICP0 complements the bovine herpesvirus 1 homolog. Vet Microbiol. 2010; 143: 37-44.

Young DF, Andrejeva L, Livingstone A, Goodbourn S, Lamb RA, Collins PL, et al. Virus replication in engineered human cells that do not respond to interferons. J Virol. 2003; 77: 2174-2181.

Received: July 24, 2012; Accepted: July 02, 2013. 